\title{
Possibilidades curriculares para o desenvolvimento dos valores da sustentabilidade
}

Cintia Azevedo Gonçalves

Marcia Regina Carletto

\begin{abstract}
Resumo
O presente estudo tem por objetivo delimitar possibilidades curriculares para o desenvolvimento dos valores da sustentabilidade, considerando-se qualquer nível de ensino. A proposta, construída a partir de pesquisa bibliográfica, tece considerações sobre os paradigmas que interferem no conceito de meio ambiente e em sua abordagem no currículo e aponta os estudos CTS e a metodologia freiriana como possibilidades pedagógicas para o desenvolvimento dos valores supracitados. A visão de mundo fragmentada interfere na abordagem dos conteúdos e na concepção ideológica sobre o que é desenvolvimento social, afetando o sentido atribuído aos mesmos. Assim,o modo como os conteúdos curriculares são trabalhados, na esfera cognitiva, oferece elementos para que o aluno tome decisões valorativas sobre os mesmos, na esfera afetiva. Os resultados indicam que os referenciais CTS e a metodologia freiriana são complementares entre si e oferecem subsídio ao desenvolvimento dos valores da sustentabilidade.
\end{abstract}

Palavras-chave: Ciência,Tecnologia e Sociedade (CTS), metodologia freiriana, valores da sustentabilidade.

\section{Abstract sustainability \\ Curricular opportunities for the development of the values of}

This study aims to define curricular opportunities for the development of the sustainability values, at any level of education. The purpose, built from literature, considers the paradigms that influence the concept of environment and its approach to the curriculum; it also sets focus in STS studies and the Freire methodology as pedagogical possibilities. The fragmented world view approach interferes to the content and ideological 
conception of what is social development and affects the meaning attributed to them. So the way curricula are worked in the cognitive area enables the student to take value decisions about them, at the affective area. The results point out that CTS references and the Freirian methodology are complementary and offer subsidies to the development of the sustainability values.

Keywords: Science, Technology and Society (CTS), Freire methodology, sustainability values.

\section{Introdução}

Indaga-se como o currículo escolar poderia abarcar as questões ambientais, subsidiando o desenvolvimento dos valores da sustentabilidade. Este é um questionamento que se faz perante as visíveis alterações no meio ambiente, que demandam a reflexão sobre o papel ativo que o ser humano tem desempenhado na modificação da natureza e degradação do meio. O contexto ambiental que se apresenta consiste em complexo desafio científico, tecnológico, econômico e especialmente cultural. (Capra, 2002; Gil et al., 2003; Carvalho, 2004; Bazzo; Pereira; Linsingen, 2008; Carletto, 2009)

O destaque ao papel central da educação como agente dinamizador do processo de formação de atitudes e comportamentos responsáveis rumo ao desenvolvimento sustentável é dado pela Organização das Nações Unidas para a Educação, a Ciência e a Cultura - UNESCO (2005). Esta assegura ser a educação indispensável para enfrentar os desafios impostos pela dinâmica social desregrada, que gera pobreza, consumo desordenado, decadência urbana, degradação ambiental, consequentes conflitos e violação dos direitos humanos.

Nessa perspectiva, enfatiza-se a visão complexa de meio ambiente, como um sistema integrado, não linear, onde as esferas da natureza, da política, da economia, da educação, da ciência, da tecnologia e da sociedade como um todo, são dependentes entre si. Todos estes sistemas estabelecem uma dialética de causas e efeitos, construindo um determinado meio ambiente, como resultado físico e social destas inter-relações. (Carletto, 1999; Capra, 2002; Ibarra; Olivé, 2003; Carvalho, 2004; Morin, 2005; Bazzo; Pereira; Linsingen, 2008)

Os autores complementam que, por ser a ação do homem que move o mundo, o cerne da questão ambiental está nos valores que embasam o comportamento humano naquele conjunto de sistemas. Portanto, pode-se considerar que a ação humana, fundamentada em determinados valores, está no centro da crise, sugerindo que uma mudança de valores é necessária para que se dê conta das questões ambientais. 
As considerações aqui propostas são baseadas em pesquisa bibliográfica e visam apontar possibilidades para uma prática educativa voltada ao desenvolvimento dos valores da sustentabilidade, prestando-se à aplicação em todos os níveis de ensino.

\section{Os valores da sustentabilidade e a influência das concepções sobre desenvolvimento social e meio ambiente}

Ao tratar sobre as possibilidades educativas rumo ao desenvolvimento sustentável, cabe refletir sobre as relações causais do comportamento humano sobre o ambiente, que concepções e valores estão latentes e que pontos de intersecção estabelecem com o currículo escolar.

$\mathrm{Na}$ cultura global do hiperconsumo e do acelerado desenvolvimento tecnológico, os problemas sócio-ambientais se agravam pelo padrão de valores intrínsecos à mercantilização não humanizada. Segundo Gil (2003), Ibarra e Olivé (2003) e Carletto (2009), os valores que preponderam na sociedade global consumista têm sido a busca por gratificações de curto prazo, o individualismo, a competitividade, a imposição dos interesses particulares das corporações aos povos e culturas economicamente menos favorecidos. Neste contexto, o desenvolvimento tecnológico tem sido refém da busca desenfreada pelo crescimento econômico.

O crescimento econômico, por sua vez, altamente exploratório do meio, vem sendo utilizado como sinônimo de desenvolvimento social. Segundo Gil (2003), é necessário desvincular o termo "desenvolvimento" de "crescimento", uma vez que crescimento envolve o incremento material quantitativo, numa escala física, mantido pela exploração crescente dos recursos naturais, portanto, insustentável em longo prazo. Já desenvolvimento significa a evolução qualitativa da vida no planeta, abrindo horizontes para modos alternativos de busca de melhorias, que não necessariamente induzam ao comportamento consumista.

No entanto, a formação de consciência coletiva, que parece ser a expressão chave para o enfrentamento do problema, necessita de uma visão diferente de desenvolvimento social da que se vem demonstrando.

A sociedade se encontra imbuída da crença no tradicional 'modelo linear de desenvolvimento', que considera correta a equação: + ciência $=+$ tecnologia $=+$ riqueza $=+$ bem estar social. Essa visão essencialista-triunfalista da ciência e tecnologia leva à idéia de que o sucesso do desenvolvimento se encontra intimamente ligado à conquista da natureza. (Ibarra; Olivé, 2003) 
Para os autores citados, a ideologia da exploração desmedida dos recursos naturais exerce, inclusive sobre os discursos ambientalistas, variados níveis de influência, transformando-os em ferramentas para manutenção do sistema.

Um exemplo é trazido por Layargues (2002), que faz referência à existência de um discurso ambientalista oficial que estimula o "consumo sustentável" pelo incentivo à reciclagem. Em contrapartida, existe a política ambientalista alternativa, não comprometida com o sistema hegemônico, que propõe o uso da pedagogia dos 3R's: Reduzir, Reaproveitar e Reciclar. Esta pedagogia enfatiza que a redução do consumo e o reaproveitamento são mais importantes que a reciclagem, pois esta acaba estimulando o consumismo, que deve ser combatido.

Segundo o autor, apesar da mensagem comumente veiculada, de que tudo o que é reciclável pode ser consumido sem culpa, nem todo material que é reciclável é realmente reciclado, sendo toneladas de material reciclável jogadas diariamente nos lixões. Assim, o termo "reciclar" camufla os interesses do consumismo a partir de uma suposta preocupação com o meio ambiente.

Outra questão a ser refletida é quanto à esperança de que a tecnologia solucione todos os problemas, sendo apenas uma questão de tempo. No entanto, a tecnologia em si não dá conta dos problemas emergentes, uma vez que não tem autonomia de dizer a quem serve. A inovação tecnológica pode ter conseqüências contrárias à sustentabilidade, na medida em que busque prioritariamente ou exclusivamente a lucratividade.

Como a raiz dos problemas ambientais está nos hábitos culturais da sociedade, a questão ambiental depende mais da cultura/comportamento social e decisões políticas do que propriamente de desenvolvimento tecnológico. (Silveira, 2007; Carletto, 2009)

Em contraposição aos valores deturpados em relação à sustentabilidade, os autores citados reforçam a necessidade de se fortalecer os valores da ecologia, que se contraponham ao espírito do hiperconsumo e da aceleração do crescimento econômico.

As considerações tecidas, até aqui, reforçam a complexidade da questão ambiental, que envolve todas as áreas do conhecimento. Sendo assim, para se contemplar o tema 'sustentabilidade', o meio ambiente teria que ter um tratamento transversal e interdisciplinar no currículo. Haja vista que, durante a formação escolar, em todos os níveis de ensino, cada disciplina curricular colabora para a construção dos conceitos acerca da realidade.

Contudo, a boa vontade dos educadores em tratar o tema meio ambiente em sua natureza complexa pode não ser suficiente. É preciso considerar que a estrutura da educação formal nem sempre se encontra preparada para a abordagem integrada dos temas ambientais, uma vez que o currículo se apresenta, em geral, fragmentado. 
A fragmentação curricular, denominada por Freire (1987) de "educação bancária", caracteriza-se por um depósito de informações, do professor para o aluno, sobre uma determinada área do conhecimento, descontextualizadas dos problemas da vida real. $\mathrm{O}$ autor a justifica como herança do cartesianismo científico que, ao fragmentar o conhecimento enquanto objeto pedagógico, dificulta aos sujeitos a visão sistêmica da realidade, necessária ao desenvolvimento da consciência crítica sobre o mundo.

A partir de Descartes, em meados do século XVII, as áreas do conhecimento passaram a ser tratadas separadamente, para melhor estudá-las. Elas passaram a ter limites bem definidos e desenvolver-se sem suficiente comunicação entre si. Isto intrincou, ao meio científico, o entendimento das repercussões sinérgicas do uso das tecnologias delas provenientes. (Carvalho, 2004)

Esta visão científica fragmentada facilitou a construção do paradigma de que a ciência é neutra, uma vez que os estudos em uma área não aparecem relacionados às demais. Em decorrência da alienação daí proveniente, passou-se a considerar que a aplicabilidade da tecnologia deve ser decidida pelas demandas sociais, enquanto o mundo vai 'naturalmente' se adaptando às mudanças em curso. (Freire, 1987; Auler, 2002; Morin, 2005; Bazzo, 2009).

Portanto, a ideologia referente à concepção linear de desenvolvimento, bem como a epistemologia da ciência que influencia a concepção fragmentada de currículo e de meio ambiente dificultam a formação dos referidos valores da ecologia. Estes dois fatores afetam diretamente a estrutura do currículo escolar, contudo, o reconhecimento de tais limites é o primeiro passo para que se consiga contorná-los, na busca de uma nova postura pedagógica, adequada à concepção de sustentabilidade.

\section{O desenvolvimento de valores como fruto de percepções cognitivas acerca da realidade}

No que se refere à formação de valores, cabe ressaltar a subjetividade em se avaliar valores e atitudes, na prática educacional. Os próprios PCN's (BRASIL, 1997, p. 39), que tratam sobre a transversalidade do tema meio ambiente no ensino, fazem a seguinte observação a respeito da formação de valores:

...não se pode deixar de salientar os limites da atuação da escola nessa formação. Vale lembrar que a educação não pode controlar todos os fatores que interagem na formação do aluno e que não se trata de impor determinados valores, mas de ser coerente com os valores assumidos, de 
possibilitar aos alunos uma discussão sobre eles e a construção de critérios para a escolha pessoal.

Isso indica que, apesar das dificuldades para que se efetive e se avalie a formação de valores, é possível que se estabeleçam possibilidades pedagógicas para a sua construção. Como acréscimo a essa reflexão, observa-se o fato de que, a partir do modo como se trata com as informações sobre o conteúdo, pode-se possibilitar que o aluno confira a ele significado afetivo.

Segundo Piaget (1996), os valores pertencem à esfera dos afetos e as informações pertencem à esfera cognitiva, sendo o conteúdo da última mais passível de submeter-se a medidas de avaliação. É na esfera cognitiva, contudo, que se dá o processo de reflexão, análise e crítica.

O autor aborda como a aquisição de regras morais, que traduzem os valores de um indivíduo, depende de processos cognitivos para a sua construção. Os valores, para Piaget (ibid) são construídos num processo evolutivo de aquisição de regras morais, que vai da heteronomia à autonomia.

A heteronomia se caracteriza pela incorporação de regras definidas a partir de um referencial externo, como, por exemplo, as regras impostas pelos pais às crianças ou as impostas pela lei aos cidadãos. Estas regras morais, no entanto, ainda não fazem parte dos valores intrínsecos do sujeito.

Já a autonomia diz respeito ao código de regras morais incorporadas autonomamente. Segundo o autor, na autonomia o indivíduo decide pelas normas que quer obedecer, a partir da verificação que faz sobre os benefícios de tais normas em seu contexto de vida. Esta verificação ou avaliação é possibilitada pelas informações que ele tem disponíveis, acerca da situação.

Com isso, o autor assegura que a aquisição de valores passa pela esfera cognitiva ou do conhecimento, onde se processa um raciocínio lógico e reflexivo sobre as informações adquiridas.

Portanto, a qualidade das informações que os educandos têm sobre a realidade, que thes permita avaliar as relações causais das ações humanas sobre o ambiente, pode influenciar na construção de valores voltados à sustentabilidade.

Porém, Silveira (2007), Bazzo, Pereira e Linsingen (2008) e Carletto (2009) salientam que a educação profissional tem cuidado prioritariamente dos conteúdos científicos - mas de modo fragmentado - ficando relegados ao segundo plano os valores relativos ao desenvolvimento e uso da ciência e da tecnologia, que exigem uma visão sistêmica de suas inter-relações.

Portanto, faz-se necessária uma reflexão filosófica aprofundada, na prática escolar, sobre a real situação do mundo e a postura adotada diante do que se ensina e se aprende, em todos os níveis da educação. 


\section{A proposta do enfoque CTS em Educação}

Dentre as possibilidades para a efetivação de uma pedagogia crítica, é apresentada uma proposta que utiliza dois referenciais complementares e permite a inserção curricular do meio ambiente como tema transversal ao currículo da formação profissional.

A proposta tem como enfoque os estudos CTS - Ciência, Tecnologia e Sociedade, que dizem respeito especialmente à postura epistemológica adotada em relação ao currículo. Ela traz uma nova visão a respeito das relações entre os três grandes conceitos que compõem o termo CTS, propondo novo paradigma para o ensino sobre ciência e tecnologia.

A abordagem metodológica proposta para o trabalho com CTS é o método Paulo Freire que, apesar de considerar os conteúdos como aspecto central, preocupa-se essencialmente com a forma como se deve abordá-los. Ou seja, oferece subsídios para nortear a prática em si, ao centrar a atenção na relação pedagógica professor-aluno-conteúdos. Sua fundamentação teórica articula-se estreitamente com a perspectiva CTS para o ensino.

\section{O Enfoque CTS}

A partir do advento da globalização e do agravamento da crise ambiental, surge a necessidade de uma nova visão de educação, que atenda à demanda da preocupação mundial com o futuro do planeta.

Em meados da década de 70, a preocupação com as repercussões sociais do uso da ciência e da tecnologia tomou lugar junto aos estudos CTS - Ciência, Tecnologia e Sociedade, no campo das ciências humanas.

A partir da percepção dos danos potenciais da tecnologia, as relações entre ciência, tecnologia e sociedade passaram a ser questionadas. Por conseguinte, passou-se a questionar o modelo linear de desenvolvimento, em que mais ciência possibilitaria mais tecnologia, consequentemente mais riqueza e, assim, mais bem-estar social, já mencionado anteriormente. Esse modelo começou a ser, então, reformulado e, a ciência, a abandonar seu lugar de neutralidade para ocupar gradativamente um lugar de atora em importantes mudanças sociais.

Já, por ocasião do Congresso Mundial sobre a Ciência, realizado em Budapeste (Hungria), em 1999, a Unesco reuniu 150 nações para discutirem sobre os efeitos da ciência e seus desdobramentos, no mundo. $O$ evento gerou o consenso, entre as nações, de estabelecer um contrato para o uso da ciência, intitulado 'Agenda para a Ciência: marco de ação'. A tônica do acordo fundamentou-se na não neutralidade da ciência e, a partir disso, estabeleceu o redirecionamento das pesquisas, considerando a responsabilidade social dos Estados em seus financiamentos. (Ibarra; Olivé, 2003) 
Nesta perspectiva política, a fundamentação dos estudos CTS consiste em desmistificar as relações entre os três conceitos que compõem a sigla - ciência, tecnologia e sociedade -, especialmente no que concerne ao espaço de investigação científica. Segundo os autores (2003, p. 121), os mitos a serem derrubados, ainda presentes na visão da comunidade científica e da sociedade, como um todo, são:

1- mito do benefício infinito - mais ciência e mais tecnologia conduzirá certamente a mais benefícios sociais;

2- mito da investigação sem limites - qualquer linha razoável de investigação sobre processos naturais é igualmente provável que produza benefício social;

3- mito da prestação de contas - as relações arbitrárias estabelecidas entre os próprios investigadores para validação científica, como a reprodutibilidade dos resultados e o controle de qualidade dão conta das responsabilidades morais e intelectuais do sistema de I+D (investigação + desenvolvimento);

4- mito da autoridade - a investigação científica proporciona uma base objetiva para resolver as disputas políticas;

5- mito da fronteira sem fim - o novo conhecimento científico gerado é autônomo com respeito a suas consequências práticas na natureza e na sociedade.

Ao contrário da educação científica e tecnológica baseada em mitos e para que a formação profissional contemple a construção de competências em prol do bem social, Lacey (2008) propõe que a prática educativa tenha como base as seguintes premissas:

a) o estabelecimento do verdadeiro lugar da ciência na sociedade contemporânea, cuja prioridade seja o fator humano;

b) o estudo das questões que influenciam a atividade científica, suas motivações e rumos assumidos, inclusive a composição das comunidades e instituições de pesquisa;

c) o estudo da relação entre ciência e bem-estar humano e a avaliação de seu valor em relação a outros valores sociais significativos;

d) a avaliação crítica sobre o modo como os fatores sociais podem, veladamente, influenciar equívocos no estabelecimento de juízos teóricos, na atividade científica;

e) a capacidade de estabelecer juízo de valor para as possibilidades tecnológicas oferecidas pela ciência, considerando as alternativas viáveis para diferentes condições sociais;

f) a capacidade de avaliar criticamente as visões concorrentes sobre os avanços tecnológicos. 
Esta compreensão paradigmática sobre a ideologia, a natureza e as implicações do conhecimento científico é que poderá proporcionar a formação de cidadãos comprometidos com um desenvolvimento tecnológico e social ético.

A adoção de políticas educacionais, neste sentido, encontra respaldo nos documentos da UNESCO (2003) para a educação. Eles enfatizam a necessidade de uma alfabetização científica e tecnológica em todas as culturas e em todos os setores da sociedade, incorporando os princípios da dimensão CTS, especialmente relacionados ao meio ambiente.

No âmbito acadêmico, a postura CTS suscita da ação pedagógica uma constante análise dos efeitos sinérgicos da ciência e dos aparatos tecnológicos na sociedade - na cultura, na saúde, no ambiente natural. Ela pode alicerçar o ensino sobre o uso das ciências e tecnologias, visando proporcionar qualidade e equidade de vida para todos.

Bazzo, Pereira e Linsingen (2008), assim como Carletto e Bazzo (2007), destacam metodologias alternativas para a introdução dos estudos CTS no currículo, experiências já praticadas tanto no Brasil como no mundo. Tais metodologias são apresentadas sob três maneiras de abordagem, quais sejam:

a. 'Enxerto CTS', que consiste em introduzir, no currículo das disciplinas de ciências, temas CTS, com o fim de levar os estudantes a terem mais consciência das implicações da ciência e da tecnologia;

b. 'Ciência e tecnologia através de CTS', que diz respeito ao ensino dos conteúdos estruturado sob a perspectiva CTS;

c. 'CTS puro' que, por sua vez, consiste em ensinar CTS de um modo que o conteúdo científico passa a ter papel subordinado, apenas para enriquecer a explicação dos conteúdos CTS. (CARLETTO; BAZZO, 2007, p. 13)

O enfoque CTS, portanto, designa um campo e um objeto de estudo, que considera os aspectos sociais da ciência e da tecnologia. No entanto, para que a prática permita as devidas reflexões propostas, apresenta-se o Método Paulo Freire como uma postura metodológica que vem ao encontro desta demanda.

\section{0 método Paulo Freire}

Ao considerar o termo 'alfabetização científica e tecnológica', mencionado pela UNESCO (2003), curiosamente, pode-se fazer um trocadilho com a 'alfabetização' - das letras - de Paulo 
Freire (1980, p.44). Este relaciona a aprendizagem da leitura com a consciência crítica sobre o mundo, afirmando que é preciso "conscientizar-se para alfabetizar-se".

Tal relação representa um elo que se pode estabelecer entre o método freiriano: 'como fazer' e a postura CTS: 'atitude, perspectiva, visão de mundo'. Ao preconizar a leitura crítica do mundo como pano de fundo para a aprendizagem das letras, Freire já estabelece o que hoje se denomina de postura CTS na educação.

Freire (1980) sustenta que o objeto a ser aprendido é parte da realidade que não é estática ou inquestionável, mas passível de mudança. Então, a aprendizagem do aluno, ao se dar de modo crítico, faz com que ele deixe de ser objeto passivo e passe a ser construtor tanto da própria aprendizagem quanto do mundo em que vive.

A pedagogia proposta por Freire (1980, p. 41) não consiste num método de ensino, mas num método de aprendizagem, mediada pelo professor. "Procurávamos uma metodologia que fosse um instrumento do educando, e não somente do educador, e que identificasse (...) o conteúdo da aprendizagem com o processo mesmo de aprender." Retoma-se aqui, portanto, a palavra 'alfabetização' em seu duplo sentido.

Nesta direção, Capra (2002) compartilha do mesmo termo, ressaltando que a 'alfabetização ecológica' é o primeiro passo para a sustentabilidade, uma vez que é ela que permite a compreensão sistêmica do mundo. Essa compreensão dos princípios comuns a todos os sistemas vivos - o planeta seria um sistema vivo - é que pode possibilitar ao ser humano viver de acordo com os princípios básicos da ecologia. Desenvolver essa visão, no aluno, depende de um método efetivo, que possa ser utilizado no ensino de qualquer conteúdo, onde a visão sistêmica de mundo permeie a prática pedagógica.

Um conceito essencial da metodologia freiriana, considerado bastante útil para a postura em questão, é o tema gerador, que consiste numa estratégia metodológica para o processo de conscientização da realidade vivida; é o ponto de onde parte o processo de construção da descoberta. Ele emerge do saber popular, da prática de vida dos alunos e, por ser buscado através da pesquisa do seu próprio universo, substitui o modo tradicional de trabalhar os conteúdos. (TOZONI-REIS, 2006)

A dialogicidade também é aspecto básico da aplicação do método Freire (1987, p. 33). É ela que dá lugar à palavra autêntica, para a qual deve ser dado espaço, no ato educativo. "Não é no silêncio que os homens se fazem, mas na palavra, no trabalho, na ação-reflexão. (...) O mundo pronunciado, por sua vez, se volta problematizado aos sujeitos pronunciantes, a exigir deles novo pronunciar." 
Com isso, entende-se que o espaço para a autoexpressão e a troca, oportunizado pelas discussões temáticas, constitui a ferramenta essencial para possibilitar a atribuição de significado ao conteúdo trabalhado. Este significado acontece pelas associações possíveis de serem feitas, no diálogo coletivo, entre o conteúdo principal e o tema gerador.

Segundo Freire (1983), a ação educativa deve ser sempre uma ação de recriação, de resignificação de significados. É isso que dá ao objeto aprendido, seu caráter modificável e, ao homem, o poder de modificá-lo.

$\mathrm{Na}$ literatura encontram-se trabalhos que propõem uma prática pedagógica que utilize a metodologia freiriana, dentro da temática CTS, como é o caso de Delizoikov (2002; 2008), Carletto (2009) e Auler (2009). Os autores situam as possibilidades de aproximação entre os referenciais teóricos, considerando os elementos comuns em suas matrizes teórico-filosóficas.

Delizoikov (2008) apresenta um modo de transpor os fundamentos do método de Freire ao ensino das ciências naturais. $O$ ato básico é levar o aluno a questionar as finalidades e interferências daquele conhecimento científico na sociedade. 0 método transposto baseia-se, em especial, nas rupturas necessárias ao aluno, em relação aos conhecimentos que ele possui sobre a realidade. Tais rupturas, balizadas pela relação dialógica professor-aluno, é que darão lugar à estruturação do novo conhecimento, o científico, de um modo significativo para o aluno. Para isso, o autor formula os três momentos pedagógicos, conforme descrito a seguir:

a) Problematização inicial: os alunos são desafiados acerca de situações levantadas, de seu dia-a-dia, que tenham a ver com os conteúdos a serem trabalhados. Aqui, o professor tem a função de coordenar e questionar posicionamentos, ao invés de responder ou dar explicações. O ponto culminante desta etapa é levar o aluno a sentir necessidade de adquirir conhecimentos que melhor expliquem as situações-problema.

b) Organização do conhecimento: neste momento, os conhecimentos são sistematicamente estudados, sob a orientação do professor. São empregadas variadas atividades com os alunos, de modo que o professor possa desenvolver a conceituação científica que fundamente a compreensão das situações problematizadas.

c) Aplicação do conhecimento: Visa abordar sistematicamente o conhecimento que vem sendo incorporado pelo aluno, a fim de possibilitar analisar e interpretar tanto as situações problematizadas como outras que possam ser compreendidas pelo mesmo conhecimento. As mais diversas atividades devem ser desenvolvidas, buscando a generalização da conceituação científica. A meta é capacitar os alunos a empregar os conhecimentos científicos, de modo que haja constante e rotineira articulação dos mesmos com as situações reais. 
Carletto (2009) propõe a aplicação dos três momentos pedagógicos, a partir da perspectiva CTS, no ensino de engenharia. O método de Avaliação de Impacto Tecnológico (AIT) visa que o processo educativo tenha implícita a postura de avaliar os impactos sociais e ambientais dos artefatos e produtos desenvolvidos pelos engenheiros.

Os autores citados apresentam possibilidades de articulação entre os dois referenciais teóricos (CTS e Freire), demonstrando sua grande valia para o exercício de um trabalho crítico em relação ao currículo.

\section{Considerações finais}

As fontes investigadas permitiram discutir a urgência e os limites ao tratamento da questão ambiental no currículo, bem como delimitar possibilidades pedagógicas para que a educação formal construa os valores voltados à sustentabilidade.

A urgência para a abordagem curricular da questão ambiental diz respeito aos valores sociais vigentes, os quais estão em desacordo com a sustentabilidade do planeta e cuja identificação proporciona uma compreensão mais clara sobre o comportamento humano no meio.

Já os fatores ideológicos e epistemológicos limitantes para tal abordagem se referem às influências da economia vigente e à visão fragmentada de ciência. Estes se apresentam como dificuldades curriculares para o desenvolvimento de um trabalho pedagógico rumo à sustentabilidade.

A complementaridade entre o enfoque CTS e a metodologia freiriana se traduz numa proposta que apresenta rico manancial teórico-prático para a realização de uma pedagogia crítica. Ela adéqua o conceito de meio ambiente à epistemologia sistêmica do conhecimento científico, contempla a ideologia coerente com os paradigmas da sustentabilidade e delineia a prática de sala de aula, de modo a oferecer um modelo completo de ação.

Contudo, para que se efetive o exercício consciente da presente proposta de trabalho, se faz importante o investimento na formação docente, preferencialmente dentro destes mesmos referenciais. Isto implica numa formação continuada que contemple horários comuns para estudos, planejamento e discussões entre professores. O apoio das instituições educacionais, neste sentido, proporcionará condições para que os docentes incorporem, gradativamente, as necessárias ações sistêmicas, transversais e intersdisciplinares no currículo escolar.

\section{Referências}


Auler, Décio. Interações entre ciência, tecnologia e sociedade no contexto da formação de professores de ciências. Florianópolis, 2002. 236f. Tese (Doutorado em Educação) Programa de Pós-graduação em educação, Universidade Federal de Santa Catarina, Florialnópolis, 2002. ; et al. Abordagem Temática: natureza dos temas em Freire e no enfoque CTS1,2

ALEXANDRIA Revista de Educação em Ciência e Tecnologia, v.2, n.1, p.67-84, mar. 2009. ISSN 1982-5153.

Bazzo, W.; Pereira, Luiz T. do V.; Linsingen, Irlan V. Educação tecnológica: enfoques para o ensino de engenharia. 2. ed. Florianópolis: UFSC, 2008.

. O que é CTS, afinal? In: SIMPÓSIO NACIONAL DE ENSINO DE CIÊNCIA E TECNOLOGIA, 1, 2009. Ponta Grossa. Anais....Ponta Grossa: PPGECT, 2009.

Brasil. Parâmetros curriculares nacionais : apresentação dos temas transversais, ética / Secretaria de Educação Fundamental. Brasília : MEC/SEF, 1997. 146p.

Capra, Fritjof. As conexões ocultas: ciência para uma vida sustentável. São Paulo: Cultrix, 2002. Carletto, M. R. Abordagem ambiental: perspectivas e possibilidades de uma prática pedagógica integradora. 1999. 115 f. Dissertação (Mestrado em Tecnologia, área de concentração Educação Tecnológica), CEFET-PR, Curitiba 1999.

; Bazzo, W. A contribuição do enfoque CTS para a abordagem da problemática ambiental no ensino de engenharia. Publ. UEPG Ci. Exatas Terra, Ci. Agr. Eng. Ponta Grossa, v. 13, n 1, pp. 716, abr. 2007.

. Avaliação de impacto tecnológico: alternativas e desafios para a educação crítica em engenharia. 2009. 287 fl. Tese (Doutorado em Educação Científica e Tecnológica) - UFSC, Florianópolis, 2009.

Carvalho, Isabel C. de M. Educação ambiental: a formação do sujeito ecológico. São Paulo: Cortez, 2004.

Delizoikov, Demétrio. Ensino de Ciências: fundamentos e métodos. São Paulo: Cortêz, 2002. . La Educación en Ciencias y la Perspectiva de Paulo Freire. ALEXANDRIA Revista de Educação em Ciência e Tecnologia. v.1, n.2, p.37-62, jul. 2008 ISSN 1982-5153. Disponível em: www.ppgect.ufsc.br/alexandriarevista/numero_3/juliana.pdf. Acesso em: jul. 2009.

FREIRE, Paulo. Conscientização: teoria e prática da libertação. São Paulo: Moraes, 1980.

Educação como prática da liberdade. 14 ed. Rio de Janeiro: Paz e Terra, 1983. Pedagogia do oprimido. 11 ed. Rio de Janeiro: Paz e Terra, 1987. GIL, D. et al. A educação científica e a situação do mundo: um programa de atividades dirigido a professores. Ciência \& Educação. v. 9, n. 1, p. 123-146, 2003. 
Ibarra, A.; Olivé, L. (Eds.) Cuestiones éticas en ciencia y tecnología en el siglo XXI: educación, ciencia y cultura. Madrid: Biblioteca Nueva, OEI, 2003. LACEY, H. Valores e atividade científica1. São Paulo: Editora 34, 2008. (Associação Filosófica Scientia Studia).

Layargues, Philippe. O cinismo da reciclagem: o significado ideológico da reciclagem da lata de alumínio e suas implicações para a educação ambiental. In: Loureiro, F.; Layargues, P.; Castro, R. (Orgs.) Educação ambiental: repensando o espaço da cidadania. São Paulo: Cortez, 2002, 179220.

Morin, Edgar. Ciência com consciência. 9. Ed. Rio de Janeiro: Bertrand Brasil, 2005.

Piaget, J. Os procedimentos de educação moral. In: Macedo, L. (Org.) Cinco estudos de educação moral. São Paulo: Casa do Psicólogo, 1996.

Silveira, R. M. C. F. Inovação tecnológica na visão dos gestores e empreendedores de Incubadoras de Empresas de Base Tecnológica do Paraná (IEBT-PR): desafios e perspectivas para a educação tecnológica. 2007. 257 f. Tese (Doutorado em Educação Científica e Tecnológica) Programa de Pós-Graduação em Educação Científica e Tecnológica, Universidade Federal de Santa Catarina, Florianópolis, 2007.

Tozoni-Reis, Marília F. de C. Temas ambientais como "temas geradores": contribuições para uma metodologia educacional crítica, transformadora e emancipatória. Educar em Revista, Curitiba, n. 27, p. 93-110, jan./jun., 2006.

UNESCO. A ciência para o século XXI: uma nova visão e uma base de ação. Brasília: UNESCO, ABIPTI, 2003. Disponível em: <http://unesdoc.unesco.org/images/0013/001315/131550POR.pdf>. Acesso em: dez 2009.

. Década das Nações Unidas da Educação para o Desenvolvimento Sustentável: 2005-2014. Documento Final Plano Internacional de Implementação. Brasília: UNESCO, mai. 2005.

Cintia Azevedo Gonçalves. Universidade Tecnológica Federal do Paraná. Psicóloga. Mestranda em Ensino de Ciência e Tecnologia - UTFPR. cintia@utfpr.edu.br

Márcia Regina Carletto. Universidade Tecnológica Federal do Paraná. Professora do Programa de Pós-Graduação em Ensino de Ciência e Tecnologia. Doutora em Educação Científica e Tecnológica. mrcarletto@utfpr.edu.br 